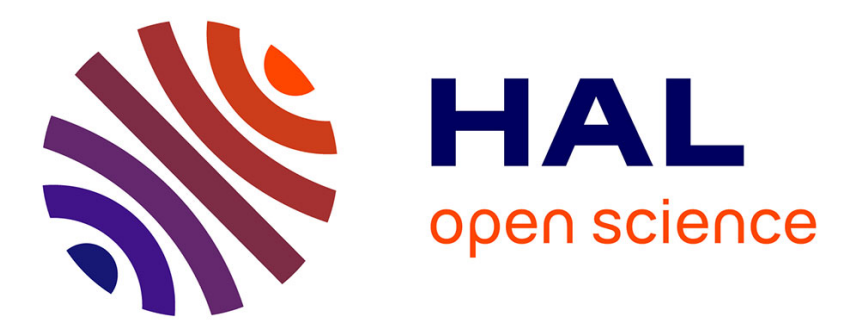

\title{
Spatial coherence of monsoon onset over Western and Central Sahel (1950-2000)
}

Romain Marteau, Vincent Moron, Nathalie Philippon

\section{To cite this version:}

Romain Marteau, Vincent Moron, Nathalie Philippon. Spatial coherence of monsoon onset over Western and Central Sahel (1950-2000). Journal of Climate, 2009, 22 (5), pp.1313-1324. 10.1175/2008JCLI2383.1. hal-00321044

\section{HAL Id: hal-00321044 \\ https://hal.science/hal-00321044}

Submitted on 15 Jan 2010

HAL is a multi-disciplinary open access archive for the deposit and dissemination of scientific research documents, whether they are published or not. The documents may come from teaching and research institutions in France or abroad, or from public or private research centers.
L'archive ouverte pluridisciplinaire HAL, est destinée au dépôt et à la diffusion de documents scientifiques de niveau recherche, publiés ou non, émanant des établissements d'enseignement et de recherche français ou étrangers, des laboratoires publics ou privés. 
$7{ }^{1}$ UMR 5210 CNRS, Centre de Recherches en Climatologie, Université de Bourgogne, Dijon, France. ${ }^{2}$ UMR 6635, CEREGE, Europôle méditerranéen de l'Arbois, France.

$9^{3}$ UFR des Sciences Géographiques et de l'Aménagement, Université d'Aix-Marseille I, Aix en Provence, France.

$11{ }^{4}$ International Research Institute of Climate and Society, Columbia University, New York, USA. ${ }^{5}$ Institut Universitaire de France 
25Corresponding author address: Romain Marteau, Centre de Recherches de Climatologie, UMR 5210

26CNRS, Université de Bourgogne, Faculté des Sciences Gabriel, 6 Bd Gabriel, 21000 Dijon, France.

27E-mail: romain.marteau@u-bourgogne.fr

\section{Abstract:}

29The spatial coherence of boreal monsoon onset over Western and Central Sahel (Senegal, Mali, 30Burkina-Faso) is studied through the analysis of daily rainfall data for 103 stations from 1950 to 312000. Onset date is defined using a local agronomic definition, i.e. the first wet day (>1 mm) of 321 or 2 consecutive days receiving at least $20 \mathrm{~mm}$ without a 7-day dry spell receiving less than 5 $33 \mathrm{~mm}$ in the following 20 days. Changing either the length and/or the amplitude of the initial wet 34spell, or the length of the following dry spell modify the long-term mean local-scale onset date 35but has only a weak impact either on its interannual variability or its spatial coherence. Onset 36date exhibits a seasonal progression from southern Burkina-Faso (mid May) to northwestern 37Senegal and Saharian edges (early August). Interannual variability of the local-scale onset date 38does not seem to be strongly spatially coherent. The amount of common or covariant signal 39across the stations is far weaker than the inter-station noise at the interannual time scale. In 40particular, a systematic spatially-consistent, advance or delay of the onset is hardly observed 41across the whole Western and Central Sahel. In consequence, the seasonal predictability of 42local-scale onset over the Western and Central Sahel associated for example with large-scale 43sea surface temperatures, is, at best, weak. 


\section{Introduction}

54The rainy season over the Sahelian belt spans only few months, mainly from July to September 55(Lamb 1978; Nicholson 1979, 1980), and is associated with the latitudinal shift of the whole

56monsoon system. Previous work has shown that the northward shift, which determines the 57large-scale onset of the rainy season across the Sudanian and Sahelian belts, usually occurs at 58the end of June, as an abrupt jump between Guinean (i.e. $5^{\circ}-8^{\circ} \mathrm{N}$ ) to Sahelian (i.e. $10^{\circ}-14^{\circ} \mathrm{N}$ ) 59latitudes (Sultan and Janicot 2000, 2003; Sultan et al. 2003; Fontaine and Louvet 2006). The 60monsoon withdrawal in late September over the Sahelian belt is much smoother (Sultan and 61Janicot 2000). "Pre-onset" scattered rains could occur over the Sahelian belt before the large62scale S-N jump, while most of the Sahelian seasonal rainfall are associated with westward63moving squall-lines (SLs) of mean horizontal extent of $\sim 500 \mathrm{~km}$ and propagation speed of 10- 
6415 m/s (i.e. Martin and Schreiner 1981; D'Amato and Lebel 1998; Laurent et al. 1998; Mathon

65et al. 2002).

66

67The timing of the start of the rainy season is crucial to decide when to plant crops (Sivakumar 681992). This is of particular importance for the Sahelian belt where economy is mostly based on 69rainfed agriculture, with weak capacity to mitigate adverse effects of interannual variability of 70rainfall (Ingram et al. 2002). In that context, any reliable prediction of the local-scale onset date 71would be of a great value to assist on time preparation of farmlands, mobilisation of seed, 72manpower and equipment, and would also reduce the risks of planting at an unfavorable time 73(Omotosho et al. 2000). Sultan et al. (2005) clearly demonstrated that the "ideal" sowing date, 74i.e. the one leading to the highest yields, is close to the large-scale onset date, defined as the 75northward jump of the Intertropical Convergence Zone (ITCZ).

76

77The definition of the onset of the rainy season over West Africa has generally followed two 78approaches: (i) a local-scale one and (ii) a large-scale one. Methods for detecting the onset of 79the rainy season at local-scale have been proposed as early as the 70's for specific Sahelian 80settings (in Niger mainly, Davey et al. 1976; Benoit 1977). Most methods rely on in-situ daily 81measurements of rainfall meeting subjective thresholds (Davey et al. 1976; Stern et al. 1981; 82Sivakumar 1988; Jolliffe and Sarria-Dodd 1994; Balme et al. 2005). These empirical thresholds 83are chosen according to the climatological properties of the rainy season as well as agronomic 84 criteria (these points will be detailed in section 3). In this approach, the onset is primarily 
85assumed as a change in the properties, frequency and/or intensity of rainfall events associated 86with the arrival of the monsoon air mass. Other parameters have also been taken into 87consideration to detect local onsets, such as evapotranspiration (Benoit 1977; Ati et al. 2002).

88

89A more recent large-scale approach is based on sub-continental indexes of observed rainfall or 90rainfall proxies such as outgoing long wave radiation (OLR) (Sultan and Janicot 2000). The 91seasonal cycles of pentad rainfall averaged over West African longitudes (e.g. $10^{\circ} \mathrm{W}-10^{\circ} \mathrm{E}$ ) 92show an alternation of steep increases and pauses (Louvet et al. 2003) during its northward 93progression. One of these pulses appears to be associated with the abrupt northward shift of the 94ITCZ, the so-called "ITCZ jump" (Sultan and Janicot 2000). The onset is thus only defined 95from the planetary-scale northward shift of the monsoon, and a single date is given for a given 96band of longitudes.

97

98The approach of Camberlin and Diop (2003) can be viewed as an intermediate approach. In 99their study, an Empirical Orthogonal Function (EOF) analysis is applied to local-scale, daily 100rainfall anomalies in Senegal for a multi-year period. A single onset date was then computed 101for the whole country as the minimum of the cumulative sum of the leading principal 102component (PC) time series on a yearly basis. This date is representative of the local-scale onset 103dates for the stations highly correlated with the leading PC, and part of local-scale interstation 104noise is filtered out through the spatial weighting provided by the EOF. 
106This brief review demonstrates that at least two different strategies are used to define the onset.

107The local-scale definition is clearly the most suitable for end-users so that they can use the 108information as a valuable decision-making parameter. In that context, three important related 109questions are explored in this paper:

110 1. How pertinent is the local-scale definition, proposed in previous studies for specific 111 settings across the Sahel, for a larger longitudinal belt? The previous definitions are 112 based on subjective thresholds chosen according to climatological and/or agronomic 113 features. The sensitivity of the onset date (in terms of mean and interannual variability) 114 to this parametrization has never been evaluated.

115 2. To what extent do the average and local-scale onset date match with the regional116 scale (i.e. as defined by Sultan and Janicot, 2000) ones? Is the abrupt jump of the ITCZ 117 noticeable across the network? These issues are related to the shape and intensity of 118 potential modes of variability of onset date. They are also intrinsically related to the 119 intensity of the spatial coherence and potential predictability of onset date.

120 3. The spatial coherence of a phenomenon is partly indicative of its potential 121 predictability: It is indeed expected that global or regional-scale sea surface 122 temperatures anomalies should induce a rather smooth, roughly spatially-uniform, 123 anomalous signal at regional-scale, at least for a flat area such as the Sahel (Moron et al. 124 2006, 2007). As forecasts of the rainy season onset is desired by user communities, an 125 estimate of its potential predicatbility is a first step toward this goal. 
127These three issues are analyzed from a 103 rain-gauge network covering Western and Central 128Sahel (Senegal, Mali and Burkina-Faso) from 1950 to 2000. Section 2 describes the different

129daily rainfall datasets. Section 3 provides the main results in terms of (i) definition of the local130scale onset date, (ii) climatological mean and characteristics of the rainfall field before and after 131the onset, (iii) interannual variability and spatial coherence of onset date. Conclusions are given 132in section 4.

\section{Daily rainfall data}

135The daily rainfall analysed in this study come from two different databases: (i) the FRIEND136AOC (Flow Regimes from International Experimental and Network Data - Afrique de l'Ouest et 137Centrale) group (http://armspark.msem.univ-montp2.fr/FRIENDAOC/), and (ii) the Senegalese 138DMN (Direction de la Météorologie Nationale) that provided us with in situ daily data of 103 139stations for the period 1950 to 2000 (Fig. 1).

\section{1a. Rainfall data}

142Data for 33 stations in Mali and 41 stations in Burkina-Faso were compiled by the FRIEND143AOC group from various sources (IRD - Institut de Recherche pour le Développement -, 144ASECNA - Agence pour la SECurité de la Navigation Aérienne en Afrique -, DMN 145Direction Météorologique Nationale - and CIEH - Comité Inter-Africain d'Etudes 146Hydrauliques -). 
148Daily rainfall amounts recorded at 29 stations come from the Senegal DMN. Most of the 149stations are located in the western part of the country while the eastern part is less sampled (Fig. 1501).

$152 b$. Filling the missing values

153Missing daily rainfall observations (less than 3\%) were replaced with a local scaling (Widmann 154et al. 2003; Ines and Hansen 2005; Schmidli et al. 2006) of daily ERA-40 rainfall. For each 155station, the closest ERA-40 grid point is chosen, and its daily rainfall is scaled so that the 156frequency of occurrence of wet day $>1 \mathrm{~mm}$ and the mean intensity of daily rainfall during wet 157days match the long-term monthly mean of the available data. Missing entries are then replaced 158by the calibrated ERA-40 rainfall for these particular days. Note that replacing the missing 159entries from May to October with a simple stochastic weather generator (Wilks 1999) leads to 160very similar results.

161

\section{Results}

163a. Agronomic definition of onset

164The local-scale agronomic definition of the onset is the most relevant to agriculture 165management. This definition is based on local-scale daily rainfall using empirical thresholds of 166rainfall that ensure enough soil moisture during planting and growing periods to avoid crop 167failure (Walter 1967; Omotosho 1990 1992; Omotosho et al. 2000). Table 1 lists the different 168thresholds used in selected previous studies dedicated to the Sahelian domain. Most of the 
169studies agree on two criteria; (i) 1 or 2 consecutive days receiving at least 20-25 mm of rainfall, 170and (ii) no 7-day dry spell in the following 30 days from the onset. The threshold of $20 \mathrm{~mm}$ 171amount was adopted following a study by ICRISAT dedicated to millet in Niger (Davey et al. 1721976; Sivakumar 1992) and corresponds to the minimum water requirement for crop survival. 173Considering at least 2 consecutive days is a reasonable choice to take into account a rain event 174that occurs across the recording time (usually between 7 and 9 a.m local time). In fact, SLs 175develop themselves mainly in late afternoon and persist sometimes during the night (Martin and 176Schreiner 1981). The 7-day dry spell after the onset is known as the "control period" and 177prevents against "false" onsets that have disastrous consequences on germination and crop 178development (Sivakumar 1992), and require farmers to sow again while the seed's stock is 179usually small (Diop 1996). Moreover, anything less than 50 percent of the weekly crop water 180requirement (CWR) will likely lead to crop failure (i.e. Omotosho et al. 2000). The CWR 181equals at least $10 \mathrm{~mm}$ across the Sahel, leading to a threshold of $5 \mathrm{~mm}$ in 7 days to define a 182dangerous limit for crop survival after the first rains.

184In the current study, a wet (dry) day is defined as a day receiving more (less) than $1 \mathrm{~mm}$ (Diop 1851999) because (i) rainfall amounts between 0 and $1 \mathrm{~mm}$ are not equally reported across 186countries and stations (i.e. synoptic or not), and (ii) considering daily amounts less than $1 \mathrm{~mm}$ 187usually increases the interstation noise (Moron et al. 2007) when determining onset. The onset 188date (OD hereafter) is defined here as the first wet day of 1 or 2 consecutive days receiving at 189least $20 \mathrm{~mm}$ without any 7-day dry spell receiving less than $5 \mathrm{~mm}$ during the following 20 days 
190counted from the onset. OD is computed from May, $1^{\text {st }}$. These criteria are obviously too

191restrictive for the driest stations and years. While less than $0.4 \%$ of station-year do not 192experience any 2-day receiving at least $20 \mathrm{~mm}$ during May-November season, $8.6 \%$ of onset 193are undefined when the post-onset 7-day dry spell receiving less than $5 \mathrm{~mm}$ in the following 20 194days is included in the definition. This percentage reaches $19 \%$ when the control period length 195is extended to 30 days from the initial wet spell. A window of 20-day is thus retained as a 196compromise between the need to consider "false" starts and a too restrictive threshold that 197 excludes many stations and years. Undefined onset dates still account for $40 \%$ of years for the 19814 stations north of $15^{\circ} \mathrm{N}$. In most of these cases, no rainy season is actually experienced with 199scattered rainy events spread across the season. In the following analyses (except for EOF in 200section 3d), the undefined onset dates $(8.6 \%)$ are replaced by the latest available onset date 201observed across the network for the given year, weakly increasing the spatial coherence over 202the northern edge of the domain.

203

204Figure 2a displays the mean onset dates averaged over the 51 years. The mean OD exhibits a 205rather regular northward shift, mixed with a secondary northwestward one over Senegal, from 206mid May (south Burkina Faso) to early August (NW Senegal and central-northern Mali). 207Respectively, $17.9 \%, 31.4 \%, 36.1 \%$ and $12.7 \%$ of onset occur in May, June, July and August 208(Fig. 2b). 
211Figure 3 shows the mean characteristics of the rainfall field averaged over the 15 days before

212and 15 days after the local-scale OD. These periods are extracted for each station on a yearly

213basis, and the frequencies of occurrence of wet days receiving respectively between 1 and 20

$214 \mathrm{~mm}$ and $>20 \mathrm{~mm}$ are computed (Fig. 3a-d) as well as the mean length of the wet and dry spells 215(Fig. 3e-h).

217Before the onset, the frequency of occurrence of wet days receiving between 1 and $20 \mathrm{~mm}$ is far 218from zero (usually 10-20\%). By contrast, the frequency of occurrence of wet days receiving > $21920 \mathrm{~mm}$ is very low (1-4\%), but this is almost fully explained by the criteria used to define OD 220(see section 3a). The mean dry spell length is rather homogeneous, usually between 4 and 6 221days, without any clear northward increase (Fig. 3g). Similarly, the mean wet-spell length is 222rather spatially uniform, between 1 and 2 days, still without any clear northward decrease (Fig. 2233e).

225From the onset, the frequency of occurrence of wet day receiving between 1 and $20 \mathrm{~mm}$ 226increases smoothly, by a factor of 2 , while the frequency of occurrence of wet day $>20 \mathrm{~mm}$ is 227roughly multiplied by 5 . The multiplication of wet days breaks up the dry spells, that are 228consistently shorter than before the onset (less than 3 days except for several northern stations, 229Fig. 3g,h) while the mean wet spell length remains shorter than 2 days (Fig. 3i,j). In other 230terms, at local-scale, the onset is usually associated with more and wetter rainy days afterwards, 231 but those wet days remain rather isolated or clustered into 2-day wet sequences. This could be 
232related to the dominant influence of SLs and the usual scarcity of long-lasting wet spells at 233these latitudes.

235Figure 4 further illustrates the relative rainfall field near the onset date, in particular its spatial 236pattern. For each station and each year, the frequency of occurrence of daily rainfall $>1 \mathrm{~mm}$ for 2372 days before (Fig. 4a), and after (Fig. 4b) the local-scale onset (and their difference, Fig. 4c) is 238computed for the whole rainfall field relocated relative to the reference station (i.e. $(0,0)$ 239location on Fig. 4). In other words, Figures 4b,c illustrate the spatial coherence of the "first 240kind", i.e. the frequency of occurrence of a wet day around a station when its onset occurs. 241Figure $4 \mathrm{a}$ is roughly similar to the mean climatological pattern of frequency of occurrence, i.e. 242a northward gradient, also visible in the mean onset date (Fig. 2). Considering the long-term 243 mean of the frequency of occurrence of any other sample of 2 days leads roughly to the same 244pattern, except that the spatial mean varies according to the seasonal cycle of rainfall (not 245shown). The occurrence of local-scale OD slightly alters this pattern (Fig. 4b), mostly through 246an increase of the frequency of occurrence of an elongated WSW-ENE shape around the 247reference station (Fig. 4c). A small asymmetric surface of $3^{\circ}-4^{\circ}\left(\sim 1^{\circ}\right)$ in longitude by $2^{\circ}\left(\sim 1^{\circ}\right)$ 248in latitude around the reference station exhibits significant (at the two-sided $90 \%$ level 249according to a Student's T test) increase of the frequency of occurrence for $75 \%(90 \%)$ of the 250time between pre- and post-onset 2 days (Fig. 4c). Thus, figure 4 suggests that local-scale OD 251seems hardly related to coherent space-time propagating features at meso- or synoptic-scale 252and/or even the planetary-scale because neither regular northward (possibly associated with an 
253abrupt jump of the ITCZ), nor westward (possibly associated with a SL) progression appears 254between panel (a) and (b) of Figure 4. Increasing the length of the time period averaged before 255and after the onset to 5, 10, 20 and 30 days is associated with a wider $\sim \mathrm{W}$-E belt of increased 256 frequency of occurrence of rainfall, probably in relation with the mean northward shift of the 257overall rain belt, especially for periods lasting at least 10 days (not shown).

259c. Spatial coherence of the onset date at interannual time scale

260The spatial coherence of the "second kind" is the possible systematic modulation of onset dates 261(or any other seasonal characteristic) at interannual time scale. Note that a weak spatial 262coherence of the "first kind" (section 3b) does not necessarily forbid this effect because a large263scale forcing could synchronize the onset dates in time, by systematically delaying or bringing 264forward the onset of the rainy season at local-scale (Moron et al. 2008). The spatial coherence 265of the OD at interannual time scale has been estimated through degrees of freedom (DOF) 266(Moron 1994; Fraedrich et al. 1995; Bretherton et al. 1999; Moron et al. 2006) and interannual 267variance of the standardized anomaly index (SAI) (var[SAI]) (Katz and Glantz 1986). The DOF 268are computed following the equation of Fraedrich et al. (1995):

269

$270 D O F=\frac{M^{2}}{\sum_{i=1}^{M} e_{i}^{2}}$

272 where $M$ is the number of stations and $e$, the eigenvalues of the correlation matrix. The DOF 273varies between 1 and the rank of the correlation matrix. In the limiting case of $e_{i}=1$ for all 
274orders, $\mathrm{DOF}=M$, that is, each station conveys independent information and the common 275 "signal" is zero. On the other hand, if the first eigenvalue accounts for all variance of the field, 276then DOF $=1$, that is, each station conveys the same information equal to the signal and the 277noise is zero. Note that due to finite length, the highest DOF expected for a $51 \mathrm{x} 103$ matrix of 278independent white noise is not 50, but rather $\sim 34$. The var[SAI] ranges between 0 (correlation 279of -1 between two equal-sized and perfectly out-of-phase samples), 1/M ( $~ 0.01$ in our case, for 280spatially independent variations), and 1 (perfect correlation between stations) (Moron et al. 2812006, 2007).

282

283Here the DOF of the local-scale OD is high (23.7) indicating a weak spatial coherence at the 284regional scale. The $\operatorname{var}[\mathrm{SAI}]$ equals 0.07 and is also close to the value associated with a white 285noise time series. For comparison, the DOF and var[SAI] equal 6.1 (respectively 4.8) and 0.36 286(respectively 0.41) for the May-November seasonal rainfall amounts (respectively frequency of 287occurrence of wet days $>1 \mathrm{~mm}$ ). Therefore, according to DOF and var[SAI], the agronomic 288OD is characterized by a considerable amount of inter-station noise, and in consequence, is 289assumed to be poorly predictable from large-scale predictors at the interannual time scale 290(Moron et al. 2006, 2007). To test the sensitivity of the spatial coherence to parametrization, 291DOF and $\operatorname{var}[\mathrm{SAI}]$ have been computed again, by changing (i) the length of initial wet spell $\left(\mathrm{L}_{\mathrm{w}}\right.$ $292=2$ to 10 days $)$ and (ii) the amount of rainfall received during the initial wet spell $\left(A_{w}=1,5\right.$, $29310,15,20,25,30,35$ and $40 \mathrm{~mm}$ ) while the other criterion (i.e. a 7-day dry spell receiving less 294than $5 \mathrm{~mm}$ in the following 20 days) is kept fixed. Note that the percentage of undefined onset 
295dates is always $<10 \%$ in mean, except when $\mathrm{A}_{\mathrm{w}}>25 \mathrm{~mm}$ and $\mathrm{L}_{\mathrm{w}}<4$ days (maximum of 296undefined onset $=19.1 \%$ for $A_{w}=40$ and $L_{w}=2$ ). As before, the missing entries are replaced 297 by the latest interannual onset date, slightly increasing the spatial coherence on the northern 298edges.

300DOF and var[SAI] are indeed very stable amongst the 81 different estimates; DOF varies 301 between $\sim 23$ and $\sim 28$ with $88 \%$ of values between 23 and 25 and var[SAI] varies between 3020.065 and 0.086. In other words, increasing the length and/or amplitude of the initial wet spell 303has a very weak impact on the spatial coherence. Even the climatological long-term mean and 304the interannual variability at local-scale are only weakly sensitive to the parametrization of $\mathrm{A}_{\mathrm{w}}$ 305and $\mathrm{L}_{\mathrm{w} . .} 52 \%$ (respectively $76 \%$ ) of the local-scale mean bias between two different estimates of 306OD are less than 5 days (respectively 10 days) in absolute value and $77 \%$ (respectively $88 \%$ ) of 307the local-scale correlations between two different estimates of OD are equal or greater than 0.7 308(respectively 0.6). The impact of the length of the control dry spell $\left(\mathrm{L}_{\mathrm{d}}\right)$ was also tested with $\mathrm{A}_{\mathrm{w}}$ 309and $\mathrm{L}_{\mathrm{w}}$ set to $20 \mathrm{~mm}$ and 2 days respectively, while $\mathrm{L}_{\mathrm{d}}$ was set equal to $5,7,9,11,13$, and 15 310days in the 20 days from the onset. Note that undefined onsets decrease almost exponentially 311 from $25 \%$ to $1 \%$ between the extreme values of $\mathrm{L}_{\mathrm{d}}$. DOF and $\operatorname{var}[\mathrm{SAI}]$ are almost stable 312 between 25 and 26 and $<0.10$ respectively. In summary, the weak spatial coherence of "second 313kind" is not related to the parametrization of the OD. 
317d. Interannual to interdecadal variability of the onset date

318To further examine the interannual variability of OD, an Empirical Orthogonal Function (EOF) 319analysis based on its correlation matrix is computed. Note that undefined onsets are left 320untouched here and that correlation matrix is computed only from pairs of available ODs. The 321leading EOF mode of OD accounts for $8.7 \%$ of the total variance consistently with the weak 322spatial coherence depicted above. By contrast, the leading EOF of the May-September seasonal 323amount (the frequency of occurrence of wet days $>1 \mathrm{~mm}$ ) accounts for $38.1 \%$ (respectively $32443.4 \%$ ) of the total variance. The second unrotated EOF mode of onset date explains less than $3256.4 \%$ of total variance. The first unrotated mode (Fig. 5a) describes a relatively coherent 326structure of OD variability mostly over Western and Central Senegal. This behaviour could be 327at least partly related to the relatively high spatial sampling (Fig. 1), but could be also related to 328a slightly stronger signal (Camberlin and Diop 2003). The corresponding leading EOFs of 329seasonal amount (Fig. 5b) and frequency of occurrence of wet days $>1 \mathrm{~mm}$ (Fig. 5c) exhibit 330larger scale patterns with loadings $>0.6$ spread all across the domain without a clear spatial 331gradient. The leading PC of onset date (respectively seasonal amount and frequency of 332occurrence) (Fig. 5d) exhibits a positive (negative) and statistically significant (at one-sided $33395 \%$ confidence level) trend, i.e. a delayed onset (decreased seasonal rainfall and frequency of 334occurrence) from 1950-2000. The median of local-scale correlations between onset on one hand 335and seasonal amount and frequency of occurrence on the other hand equals only -0.35 . 
337In order to analyse the relationships between the local-scale and the regional-scale onset date as 338defined by Sultan and Janicot (2000) through the S-N jump of the ITCZ the local-scale OD are 339extracted from 1968 (available online at http://www.lodyc.jussieu.fr/ bslod/monsoon.htm). 340Note that DOF of local-scale OD for the 1968-2000 period equals $\sim 19$, but this apparent higher 341 spatial coherence could be an artefact of the decrease of the matrix rank from 50 to 32 . The 342correlations between the large-scale and the 103 local-scale ODs are between -0.54 and 0.41 , 343 with only 7 values being significant at the two-sided $95 \%$ level according to a random phase 344test (Janicot et al. 1996). Moreover, the correlation between regional-scale OD as defined by 345Sultan and Janicot (2000) and a regional index (SAI) or the leading PC of onset date equals 346only 0.06 and 0.24 (both values are not significant at the two-sided 90\% level). The large-scale 347onset is divided in 3 terciles of early $(1969,1982,1985,1973,1978,1994,1996,1999,1993$, 3481974, 1977), near-normal (1990, 1992, 1975, 1980, 1970, 1983, 1986, 1968, 1976, 1971, 1979) 349and late $(1981,1972,2000,1985,1988,1997,1984,1989,1987,1998,1991)$ jumps of the 350ITCZ. The local-scale OD anomalies are then averaged for the three sets of years. There is a 351considerable amount of inter-station noise for each of the terciles and the number of stations 352where the OD anomaly is significantly different from zero (based on a one-sided t-test at the $35390 \%$ confidence level) is always less than $15 \%$ (not shown).

355Lastly, the teleconnections between local scale OD and four sea surface temperature (SST) 356indices, capturing ocean sectors known for exerting an influence over West African Monsoon 357were considered (i.e. Nicholson 1986; Ropelewski and Halpert 1987; Rowell et al. 1995; 
358Nicholson and Kim 1997; Janicot et al. 1996, 2001). These indices include the east equatorial 359Pacific (NINO3.4, $\left.170^{\circ} \mathrm{W}-120^{\circ} \mathrm{W} ; 5^{\circ} \mathrm{S}-5^{\circ} \mathrm{N}\right)$, the North Tropical Atlantic (NATL: $60^{\circ} \mathrm{W}-30^{\circ} \mathrm{W}$; $3605^{\circ} \mathrm{N}-20^{\circ} \mathrm{N}$ ), the South Tropical Atlantic (SATL: $30^{\circ} \mathrm{W}-10^{\circ} \mathrm{E} ; 0^{\circ}-20^{\circ} \mathrm{S}$ ) and the Guinean Gulf 361(GGUI: $\left.10^{\circ} \mathrm{W}-10^{\circ} \mathrm{E} ; 5^{\circ} \mathrm{S}-5^{\circ} \mathrm{N}\right)$. Figure 6 displays distribution of correlation coefficients 362between local-scale OD and each SST indices averaged over May-July (i.e. including 85\% of 363the local-scale onset, Fig. 1) for 1950-2000, 1950-1969 and 1970-2000. At least 50\% of 364correlation coefficients are between -0.2 and +0.2 and the significant value are usually scattered 365in space (not shown). In summary, the teleconnections between the SST related to the ENSO 366phenomenon, the Tropical Atlantic dipole, or Guinea Gulf and local-scale OD seem weak.

\section{7}

\section{Conclusion}

369The main goal of this paper was to analyze the spatial coherence, robustness and the interannual 370variability of the local-scale onset date (OD) of the boreal summer monsoon over Western and 371Central Sahel (Mali, Burkina-Faso, Senegal) from a network of 103 rain gauges (Fig. 1) with 372almost complete records from 1950 to 2000. The local-scale OD is first defined as the first wet 373 day $>1 \mathrm{~mm}$ of one or two consecutive day receiving at least $20 \mathrm{~mm}$ without any 7 -day dry spell 374receiving less than $5 \mathrm{~mm}$ in the following 20 days from the onset. This local-scale definition 375follows previous studies (Stern et al. 1981; Sivakumar 1988; Omotosho 1990; Jolliffe and 376Sarria-Dodd 1994; Omotosho et al. 2000; Dodd and Jolliffe 2001) and is best suited for end377user purposes since it explicitly takes into account the rainfall demand for crop seeding and 378survival during the first stages of growth. This analysis complements previous similar studies 
379(summarized in Table 1) which typically considered a smaller subset of stations and did not 380deeply investigate the sensitivity of the mean OD and its variability related to the subjective 381parameters used in its definition such as the length and amplitude of the initial wet spell.

383The spatial coherence of OD is analyzed from two points of view: (i) a quasi-instantaneous 384pattern of rainfall when onset date occurs at a particular station (Fig. 4) and (ii) the 385 synchronization of onset dates at interannual time scale, i.e. the possible systematic modulation 386of onset dates across the Sahelian band (Fig. 5). The spatial coherence of the "first kind" 387exhibits a small, significant increase of frequency of occurrence of rainfall relative to pre-onset 3882-day (Fig. 4c). This could be associated with a range of factors, from convective cells to meso389 convective clusters that probably trigger the local-scale onset. The spatial coherence of the 390 "second kind" is analyzed through empirical estimates of the degrees of freedom (DOF) or 391interannual variance of the Standardized Anomaly Index (var[SAI]). Both estimates suggest a 392 weak spatial coherence, i.e. the onset date is hardly systematically synchronized at interannual 393time scales. This is also demonstrated by the weak amount of variance accounted for by the 394leading EOF (Fig. 5a). These results contrast with the seasonal amount and the frequency of 395occurrence which exhibit a large-scale pattern across the whole belt analyzed (Fig. 5b,c). The 396weak spatial coherence of the "second kind" is almost independent of the parametrizations used 397in the definition of the onset date. 
399These suggest that large-scale potential forcing seems unable to systematically synchronize the 400occurrence of the first rains above a fixed threshold across the western and central Sahel. The 401occurrence of the local-scale onset could be hardly viewed as a systematic event across year 402and station, but merely a complex product of the multi-scale phenomena that produce rainfall 403over this area. The discrepancy between the local-scale OD defined here and the regional-scale 404onset defined by the northward jump of the monsoon is especially puzzling and needs further 405investigation. It is possible that local-scale onset as defined here could be associated either with 406a localized convective event, even before the S-N jump of the ITCZ, or with a meso-scale 407squall line. But even in this latter case, the timing of occurrence, size, location and track of the 408first squall line of the rainy season are hardly reproducible from one year to the next. In other 409 words, there are too many different phenomena, or different scales of motion, that could lead to 4105-40 mm rainy event in 2-10 days at local-scale. If the northward jump of the monsoon 411enhances the probability of such events across the Sahel, the fact that ITCZ has moved to its 412northernmost seasonal location, does not necessarily induce local-scale onset everywhere at the 413same moment or even on a short time step.

415An important consequence is that local-scale OD appears to show little potential predictability 416based on large and regional-scale boundary conditions such as sea surface temperatures and/or 417soil moisture (Folland et al. 1986; Philippon and Fontaine 2002; Douville et al. 2007). This is 418because the regional-scale seasonal potential predictability implies that the variable of interest 419shares a variable, but significant, amount of common or covariant information at this scale, at 
420least for a flat area as Sahel. The fact that seasonal rainfall amount and frequency of occurrence 421are far more spatially-coherent than the onset date (i.e. DOF equals respectively $6.1,4.8$, and 42223-28) suggests that most of the seasonal predictability of rainfall over the Sahelian belt is 423actually not associated with a systematic delay or advance of the local-scale onset as defined 424here, but stands out for example as a seasonally-varying or constant systematic modulation of 425the frequency of occurrence of rainfall across the season (Moron et al. 2007). This is not a 426trivial result, because local-scale onset sometimes conveys a spatially-consistent signal and 427potential predictability, as in Indonesia (Moron et al. 2008). This analysis emphasizes also the 428need to carefully examine the context of any local-scale analysis of the onset, because the weak 429spatial coherence implies a potential large uncertainty due to random sampling. More work is 430also needed to look at other definitions of the onset, for example integrating the daily rainfall in 431time and/or in space. The spatial noise is not necessarily evenly distributed across the scales and 432it would be interesting to look at intermediate scales between the local-scale and large-scale 433onsets. In particular, any definition that filters out some of the local-scale noise as the 434cumulative daily rainfall anomalies (Camberlin and Diop 2003; Liebmann et al. 2007) is 435especially appealing in this context. The apparent spatial increase of the signal over Western 436and Central Senegal (Fig. 5a) warrants also further studies.

438Acknowledgements: We acknowledge the FRIEND-AOC group and Senegal DNM for 439providing us the rainfall data. R. Marteau is partly supported by the AMMA program. Based on 440a French initiative, AMMA was built by an international scientific group and is currently 
441funded by a large number of agencies, especially from France, UK, US and Africa. It has been 442the beneficiary of a large financial contribution from the European Community's sixth 443Framework Research Program. Detailed information on scientific coordination and funding is 444available on the AMMA International web site: http://www.amma-international.org. ECMWF 445ERA-40 data used in this study have been freely obtained from the ECMWF Data Server 446(http://www.ecmwf.int). We thank Gil Mahé and Benjamin Sultan for fruitful discussions. 447Lastly, we thank two anonymous reviewers and the editor of this paper (D. Straus) for their 448constructive comments which help us on clarifying the goals and results of our paper, and lastly 449Bradfield Lyon (IRI, Columbia University) for his careful reading of the revised version of this 450paper

452References

453Ati, O.F., Stigter, C.J., and Oladipo, E.O., 2002: A comparison of methods to determine the 454 onset of the growing season in Northern Nigeria. Int. J. Climatol., 22, 731-742.

455Balme, M., Galle, S. and Lebel, T., 2005: Démarrage de la saison des pluies au Sahel :

456 variabilité aux échelles hydrologique et agronomique, analysée à partir des données EPSAT-Niger. Sécheresse, 16, 15-22.

458Benoit, P., 1977: The start of the growing season in Northern Nigeria. Agric. For. Meteorol., 459 18, 91-99.

460Bretherton, C.S., Widmann, M., Dymnikov, V.P., Wallace, J.M., and Bladé, I., 1999: The 461 effective number of degrees of freedom of a time varying field. J. Clim., 12, 1990-2009. 
462Camberlin, P. and Diop, M., 2003: Application of daily rainfall principal component analysis

463 to the assessment of rainy season characteristics in Senegal. Clim. Res., 23, 159-169.

464D'Amato, N. and Lebel, T., 1998: on the characteristics of the rainfall events in the Sahel with

465 a view to the analysis of climatic variability. Int. J. Climatol., 18, 955-974.

466Davey, E.G., Mattei, F., and Soloman, S.I., 1976: An evaluation of climate and water

467 resources for the development of agriculture in the Soudano-Saelian zone of West

$468 \quad$ Africa. WMO Special Environment Report No. 9.

469Diop, M., 1996: A propos de la durée de la saison des pluies au Sénégal. Sécheresse, 7, 7-15.

470Diop, M., 1999: Caractérisation du facteur hydrique en agriculture pluviale au Sénégal: le cas

471 de l'arachide et du mil. Thèse de doctorat, Université de Bourgogne, Dijon, 185 p.

472Dodd, D.O.S. and Jolliffe, I.T., 2001: Early detection of the start of the wet season in semiarid

473 tropical climates of western Africa. Int. J. Climatol., 21, 1251-1262.

474Douville, H., Conil, S., Tyteca, A., and Voldoire, A., 2007: Soil moisture memory and West

475 African monsoon predictability: artefact or reality? Clim. Dyn., DOI 10.1007/s00382-

$476 \quad$ 006-0207-8.

477Folland, C.K., Palmer, T.N., and Parker, D.E., 1986: Sahel rainfall and worldwide sea

$478 \quad$ temperatures. Nature, 320, 602-607.

479Fontaine, B. and Louvet, S., 2006: Sudan-Sahel rainfall onset : definition of an objective

480 index, types of years, and experimental hindcast. J. Geophys. Res., 111, 481 doi:10.1029/2005JD007019.

482Fraedrich, K., Ziehmann, C., and Sielmann, F., 1995: Estimates of spatial degrees of freedom. 
484Ines, A.V.M. and Hansen, J.W., 2005: Bias correction of daily GCM outputs for crop 485 simulation studies. Agric. For. Meteorol., 138, 44-53.

486Ingram, K.T., Roncoli, M.C., and Kirshen, P.H., 2002: Opportunities and constraints for 487 farmers of west Africa to use seasonal precipitation forecasts with Burkina-Faso as a $488 \quad$ case study. Agric. Syst., 74, 331-349.

489Janicot, S., Moron, V., and Fontaine, B., 1996: Sahel drought and ENSO dynamics. Geophys. 490 Res. Lett., 23, 515-518.

491Janicot, S., Trzaska, S., and Poccard, I., 2001: Summer Sahel-ENSO teleconnection and 492 decadal time scale SST variations. Clim. Dyn., 18, 303-320.

493Jolliffe, I.T. and Sarria-Dodd, D.E., 1994: Early detection of the start of the wet season in 494 tropical climates. Int. J. Climatol., 14, 71-76.

495Katz, R.W. and Glantz, M.H., 1986: Anatomy of a rainfall index. Mon. Wea. Rev., 114, $496 \quad 764-771$.

497Lamb, J.P., 1978: Case studies of tropical Atlantic surface circulation patterns associated 498 with subsaharan weather anomalies: 1967 and 1968. Mon. Wea. Rev., 106, 1052-1055. 499Laurent, H., D'Amato, N., and Lebel, T., 1998: How important is the contribution of the 500 Mesoscale Convective Complexes to the Sahelian rainfall? Phys. Chem. Earth, 23, 629501 633.

502Liebman, B., Camargo, S., Seth, A., Marengo, J.A., Carvalho, L.M.V., Allured, D., Fu, R., 
504 observations and the ECHAM 4.5 Atmospheric General Circulation Model. J. Clim., 20, $505 \quad 2037-2050$.

506Louvet, S., Fontaine, B., and Roucou, P., 2003: Active phases and pauses during the 507 installation of the West African monsoon through 5-day CMAP rainfall data (1979508 2001). Geophys. Res. Lett., 30, doi:10.1029/2003GL018058.

509Martin, D.W., and Schreiner, A.J., 1981: Characteristics of West African and east Atlantic 510 cloud clusters: a survey from GATE. Mon. Wea. Rev., 109, 1671-1688.

511Mathon, V., Laurent, H., and Lebel, T., 2002: Mesoscale convective system rainfall in the 512 Sahel. J. Appl. Meteo., 41, 1081-1092.

513Moron, V., 1994: Guinean and Sahelien rainfall anomaly indices at annual and monthly scales (1933-1990). Int. J. Climatol., 14, 325-341.

515Moron, V., Robertson, A.W., and Ward, M.N., 2006: Seasonal predictability and spatial 516 coherence of rainfall characteristics in the tropical setting of Senegal. Mon.Wea. Rev., 134, 3248-3262.

518Moron, V., Robertson, A.W., Ward, M.N., and Camberlin, P., 2007: Spatial coherence of 519 tropical rainfall at the regional scale. J. Clim., 20, 5244-5263.

520Moron, V., Robertson, A.W., and Boer, R., 2008: Spatial coherence and seasonal 521 predictability of monsoon onset over Indonesia. J. Clim., in press.

522Nicholson, S., 1979: Revised rainfall series for the West-African subtropics. Mon. Wea. 
524Nicholson, S., 1980: The nature of rainfall fluctuations in sub-tropical Africa. Mon. Wea. Rev., 108, 473-484.

526Nicholson, S., 1986: The quasi-periodic behavior of rainfall variability in Africa and its 527 relationship to the Southern Oscillation. Arch. Meteo. Geophys. Bio., $528 \quad$ A 34, 311-348.

529Nicholson, S. and Kim, J., 1997: The relationship of the El Niño-Southern Oscillation to African rainfall. Int. J. Climatol., 17, 177-135.

531Omotosho, J.B., 1990: Onset of thunderstorms and precipitation over northern Nigeria. Int. J. Climatol., 10, 849-860.

533Omotosho, J.B., 1992: Long-range prediction of the onset and end of the rainy season in the West African Sahel. Int. J. Climatol., 12, 369-382.

535Omotosho, J.B., Balogun, A.A., and Ogunjobi, K., 2000: Predicting monthly and seasonal 536 rainfall, onset and cessation of the rainy season in West Africa using only surface data. Int. J. Climatol., 20, 865-880.

538Philippon, N., and Fontaine, B., 2002: The relationship between the Sahelian and previous 2nd 539Guinean rainy seasons: a monsoon regulation by soil wetness ? Ann. Geophysicae, 20, 575-582. 540Ropelewski, C.F. and Halpert, M.S., 1987: Global and regional scale precipitations associated with El Niño/Southern Oscillation. Mon.Wea. Rev., 115, 985-996. 
542Rowell, D.P., Folland, C.K., Maskell, K., and Ward, M.N., 1995: Variability of summer

543 rainfall over tropical North Africa (1906-1992): Observations and modelling. Quart. J.

$544 \quad$ Meteo. Soc., 113, 669-674.

545Schmidli, J., Frei, C., and Vidale, P.L., 2006: Downscalling from GCM precipitation : a

546 benchmark for dynamical and statistical downscalling methods. Int. J. Climatol., 26, $547 \quad 679-689$.

548Sivakumar, M.V.K., 1988: Predicting rainy season potential from the onset of rains in

549 southern sahelian and sudanian climatic zones of West Africa. Agric. For. Meteo., 42, $550 \quad 295-305$.

551Sivakumar, M.V.K., 1992: Empirical analysis of dry spells for agricultural applications in 552 West Africa. J. Clim., 5, 532-539.

553Stern, R.D., Dennett, M.D., and Garbutt, D.J., 1981: The start of the rains in West Africa. Int. 554 J. Climatol., 1, 59-68.

555Sultan, B., and Janicot, S., 2000: Abrupt shift of the ITCZ over West Africa and intra-seasonal 556variability. Geophys. Res. Lett., 27, 3353-3356.

557Sultan, B., Janicot, S., and Diedhiou, A., 2003: The West African monsoon dynamics. Part I : 558 Documentation of intraseasonal variability. J. Clim., 16, 3389-3406.

559Sultan, B., and Janicot, S., 2003: The West African monsoon dynamics. Part II : The "pre560 onset" and the "onset" of the summer monsoon. J. Clim., 16, 3407-3427.

561Sultan, B., Baron, C., Dingkuhn, M., Sarr, B., and Janicot, S., 2005: Agricultural impacts of 
562 the large-scale variability of the West African monsoon. Agric. For. Meteo., 128, 93$563 \quad 110$.

564Walter, M.W., 1967: Length of rainy season in Nigeria. Niger. Geogr. J., 10, 123-128.

565Widmann, M., Bretherton, C.S., and Salaté, P., 2003: Statistical precipitation downscaling

566 over the Northwestern United States using numerically simulated precipitation as a 567 predictor. J. Clim., 16, 799-816.

568Wilks, D.S., 1999: Interannual variability and extreme-value characteristics of several 569 stochastic daily precipitation models. Agric. For. Meteorol., 93, 153-169.

570 


\section{Figures captions}

572Figure 1: Location of the 103 Sahelian rain-gauge used in this study.

573Figure 2: (a) Climatological (1950-2000) local-scale onset date (b) distribution of cumulative 574 frequency of the local onset date $(25,50$ and 75 percentiles are indicated by vertical dashed 575line)

576Figure 3: Rainfall field statistics averaged over the 15 days before (left column) and from 577(right column) the local-scale onset date. Mean frequency of occurrence (x 100) of wet days 578receiving between 1 and $20 \mathrm{~mm}(\mathrm{a}, \mathrm{c})$ and more than $20 \mathrm{~mm}(\mathrm{~b}, \mathrm{~d})$. Mean wet spell length (e, f) 579and dry spell length $(\mathrm{g}, \mathrm{h})$ in tenth of day.

580Figure 4: Mean frequency of occurrence of daily rainfall $>1 \mathrm{~mm}$ for 2-day before (a) and from 581(b) the local-scale onset, and the "(b) minus (a)" difference (c). All fields are relocated 582relatively to the reference station (coordinates $=0,0$ ). In the latter panel, the simple (double) 583circles indicate a relative location where $75 \%(90 \%)$ of the differences (b)-(a) are significant at 584the two-sided $90 \%$ level according to a Student's T test.

585Figure 5: (a) Leading unrotated empirical orthogonal function (EOF) modes of the local-scale 586onset date, expressed as loadings, i.e. correlation between the corresponding Principal 587Component (PC) and the raw data. (b) Leading unrotated EOF of seasonal (MJJAS) amount of 588rainfall. (c) Leading unrotated EOF of seasonal (MJJAS) frequency of occurrence of rainfall > $5891 \mathrm{~mm}$. Bold squares displaying correlations statistically significant at the two-sided 95\% 590confidence level according to a Bravais-Pearson test. (d) leading principal component 
591timeseries of onset date (bars), seasonal amount (circle) and frequency of occurrence of rainfall 592(upper triangle).

593Figure 6: Boxplot of correlation coefficients between local-scale onset date and NINO3.4, 594Tropical Atlantic dipole and Guinea gulf SST index for periods 1950-2000, 1950-1969 and 5951970-2000. Boxes are bounded by the first quartite, and thirct quartile of the distribution and the 596internal horizontal line is the medtan. Whiskers extend from the box out to the most extreme597tata value within 1.5 by the interquartite range. The boxes have lines at the lower quartile, 598median, and upper quartile values. The whiskers are lines extending from each end of the boxes 599to show the extent of the range of the data within 1.5 by the interquartile range from the upper 600and lower quartiles. The outtiers are displayed by a cross. Outliers, displayed by a cross, are 601data with values beyond the ends of the whiskers. Italic values indicate the number of local602scale correlations significant at two-sided 95\% confidence level according to a random phase 603test (Janicot et al. 1996).

604 


\section{Tables captions}

606Table 1. Criteria of the agronomic definitions of the local-scale onset date of the rainy season

607used in selected previous studies. All of these definitions start from daily rainfall observed at 608rain-gauge stations.

609

610

611

612

613

614

615

616

617

618

619

620

621

622

623

624

625 


\begin{tabular}{|c|c|c|c|c|c|}
\hline Authors & Data & Details of definitions & Study area & $\begin{array}{c}\text { Number of } \\
\text { stations }\end{array}$ & $\begin{array}{l}\text { Study } \\
\text { period }\end{array}$ \\
\hline Stern et al. (1981) & $\begin{array}{l}\text { Daily } \\
\text { rainfall }\end{array}$ & $\begin{array}{l}-2 \text { successive days } \\
\text { - receiving at least } 20 \mathrm{~mm}\end{array}$ & $\begin{array}{c}\text { Transect S/N } \\
\text { Benin, } \\
\text { Nigeria, } \\
\text { Niger, Mali }\end{array}$ & 11 stations & 1934-1965 \\
\hline Sivakumar (1988) & $\begin{array}{l}\text { Daily } \\
\text { rainfall }\end{array}$ & $\begin{array}{l}\text { - } 3 \text { consecutive days } \\
\text { - accumulating at least } 20 \mathrm{~mm} \\
\text { - no dry period of } 7 \text { or more } \\
\text { consecutive days } \\
\text { in the following } 30 \text { days }\end{array}$ & $\begin{array}{c}\text { Niger } \\
\text { Burkina-Faso }\end{array}$ & 58 stations & $\begin{array}{c}25 \text { Years } \\
\text { (not } \\
\text { specified) }\end{array}$ \\
\hline $\begin{array}{l}\text { Omotosho (1990, } \\
\text { 1992) }\end{array}$ & $\begin{array}{l}\text { Daily } \\
\text { rainfall }\end{array}$ & $\begin{array}{l}\text { - first } 4 \text { falls receiving at least } 10 \\
\mathrm{~mm} \\
\text { - no dry spell of } 7 \text {-day between any } \\
2 \text { such rains }\end{array}$ & $\begin{array}{c}\text { Northern } \\
\text { Nigeria \& } \\
\text { West Africa }\end{array}$ & 3 stations & 1973-1988 \\
\hline $\begin{array}{l}\text { Dodd and Jolliffe } \\
\text { (1994) }\end{array}$ & $\begin{array}{l}\text { Daily } \\
\text { rainfall }\end{array}$ & $\begin{array}{l}\text { - } 5 \text { consecutive days (with at least } \\
\text { two other wet } \\
\text { days in the period) } \\
\text { - accumulating at least } 25 \mathrm{~mm} \\
\text { - no dry period of } 7 \text { or more } \\
\text { consecutive days in the } \\
\text { following } 30 \text { days }\end{array}$ & Burkina-Faso & 22 stations & 1902-1989 \\
\hline
\end{tabular}

630Table 1. Criteria of the agronomic definitions of the local-scale onset date of the rainy season 631 used in selected previous studies. All of these definitions start from daily rainfall observed at 632rain-gauge stations. 
641

642

643

644

645

646

647

\section{FIGURES:}

649

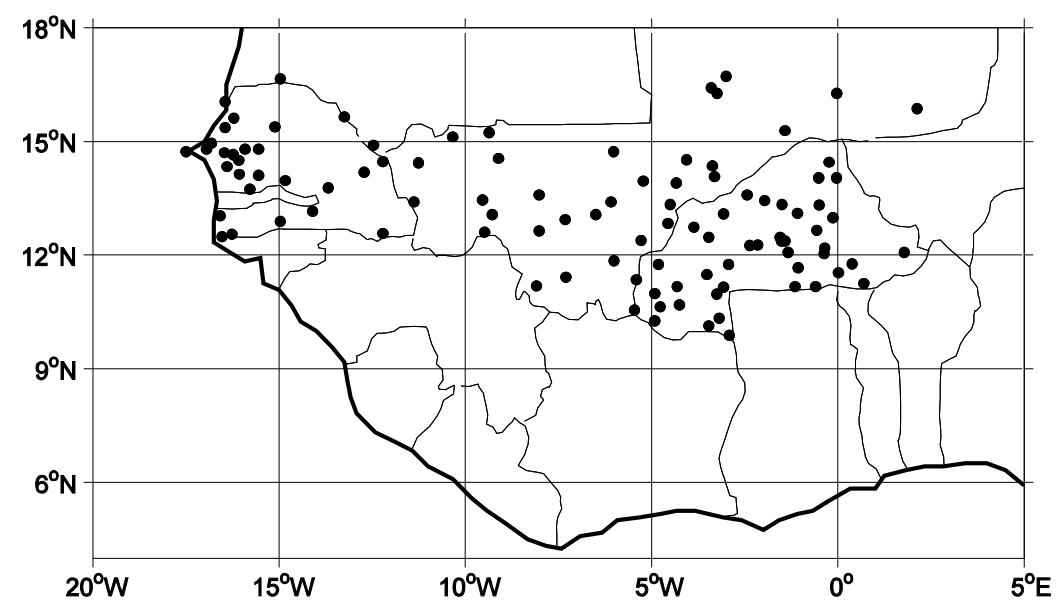

650

651Figure 1. Location of the 103 Sahelian rain-gauge stations used in this study.

652 
(a) Mean onset date

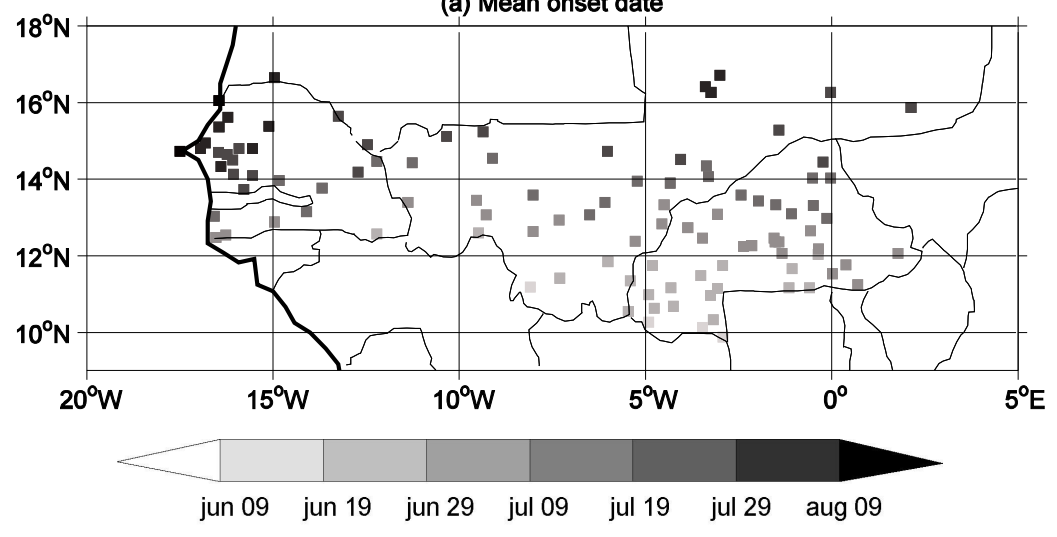

653

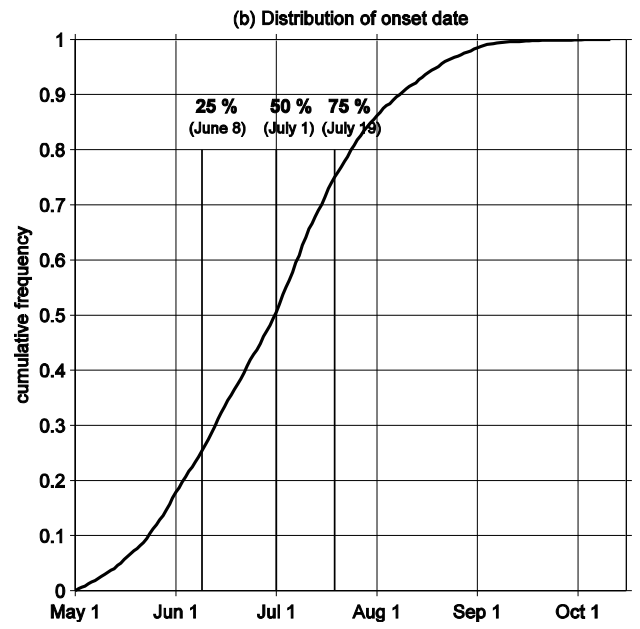

654Figure 2 : (a) Climatological (1950-2000) local-scale onset date (b) distribution of cumulative 655 frequency of the local onset date $(25,50$ and 75 percentiles are indicated by vertical dashed 656line).

657
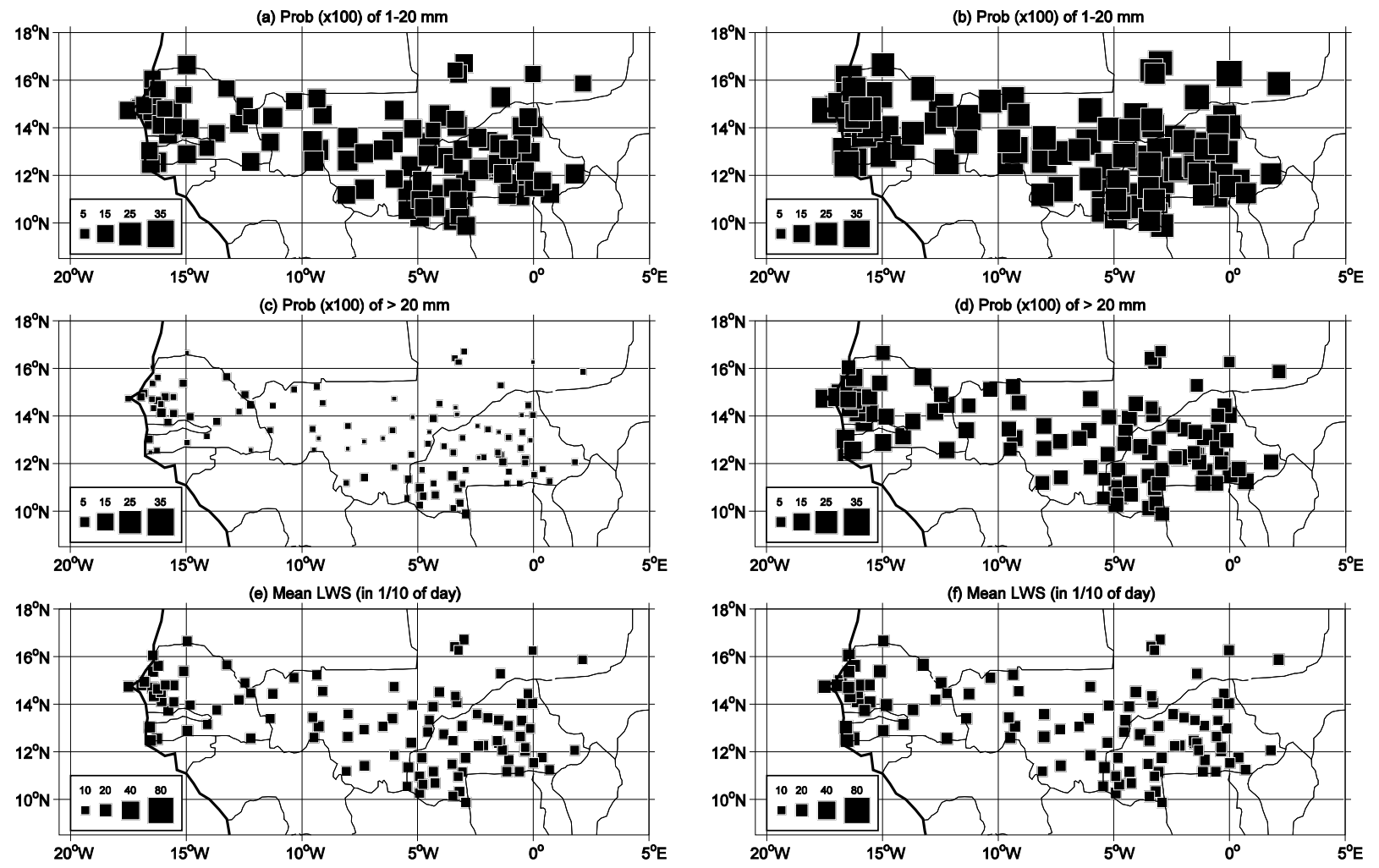

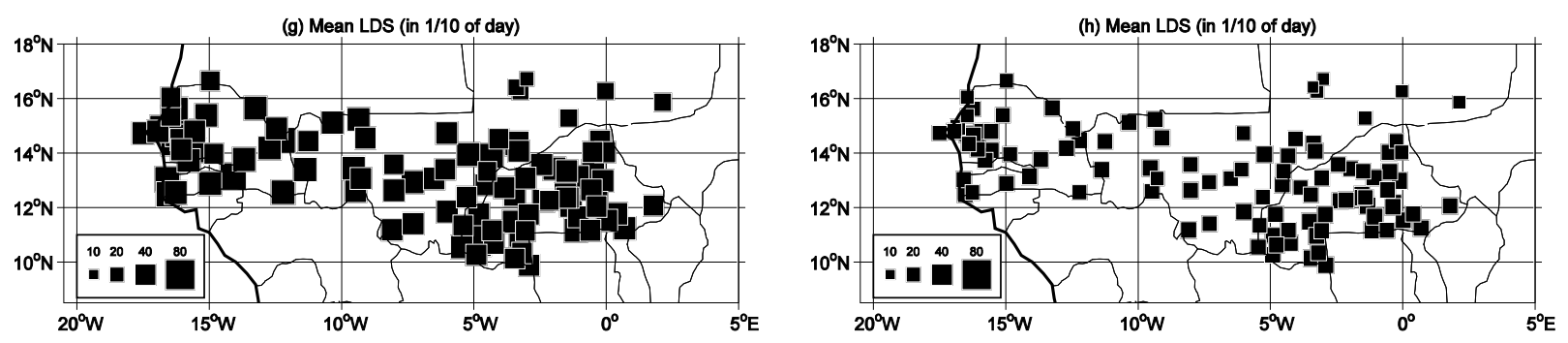

659

660Figure 3. Rainfall field statistics averaged over the 15 days before (left column) and from (right 661 column $)$ the local-scale onset date. Mean frequency of occurrence $(\times 100)$ of wet days receiving 662between 1 and $20 \mathrm{~mm} \mathrm{(a,c)} \mathrm{and} \mathrm{>} 20 \mathrm{~mm}$ (b, d). Mean wet spell length (e, f) and dry spell 663length $(\mathrm{g}, \mathrm{h})$ in tenth of day.

664

665

666

667 

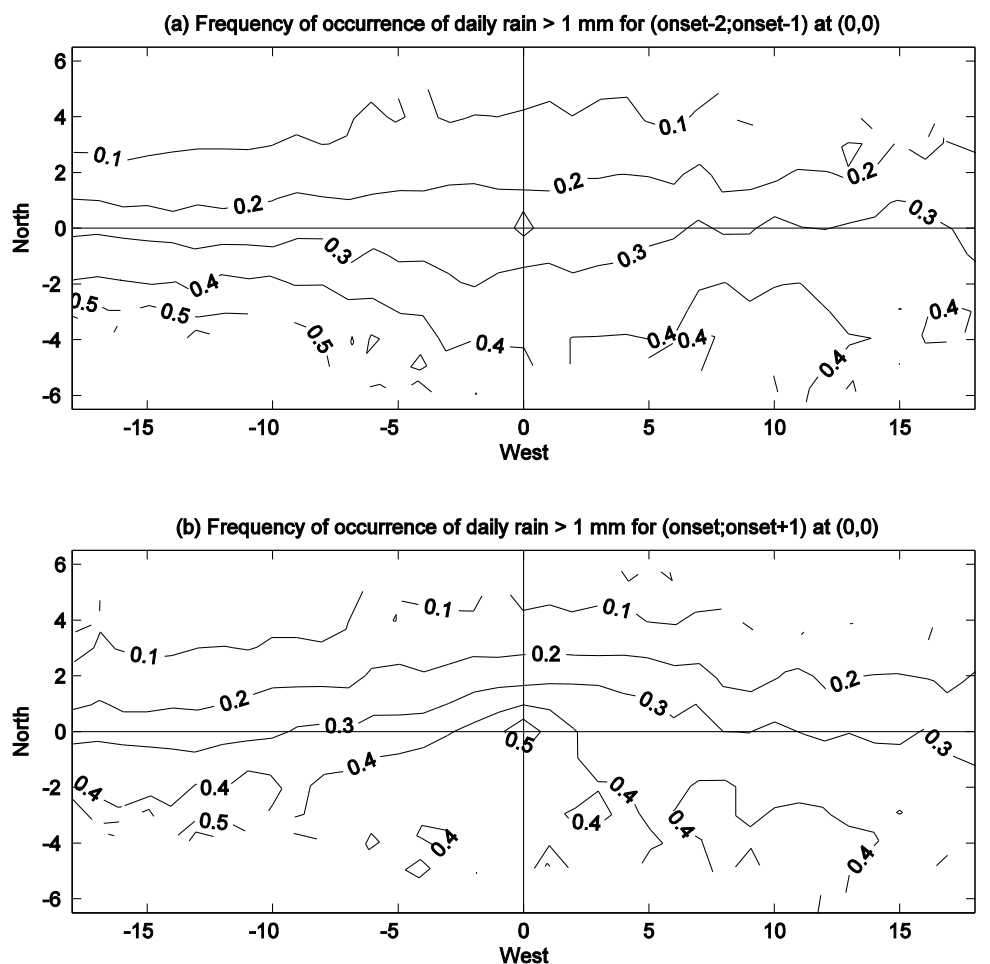

668

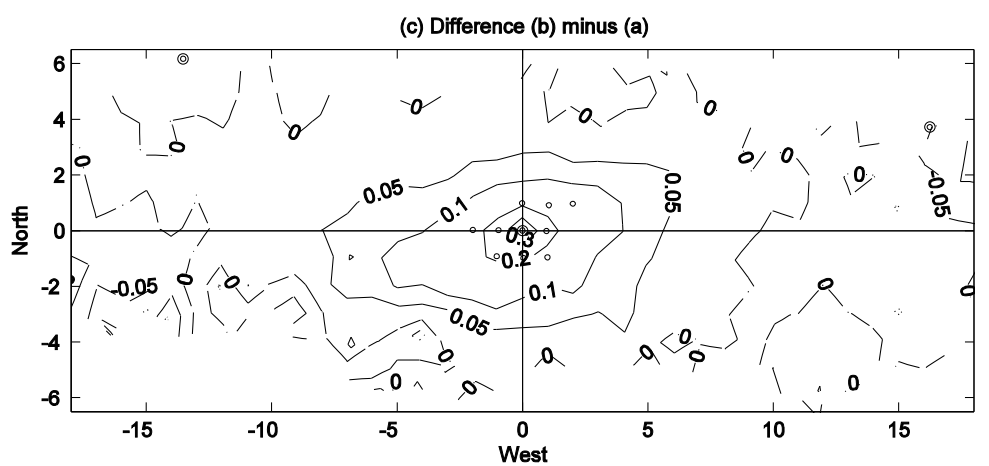

669Figure 4. Mean frequency of occurrence of daily rainfall $>1 \mathrm{~mm}$ for 2-day before (a) and from 670(b) the local-scale onset, and the "(b) minus (a)" difference (c). All fields are relocated 671relatively to the base station (coordinates $=0,0$ ). In the latter panel, the simple (double) circles 672 indicate a relative location where $75 \%$ (90\%) of the difference (b)-(a) are significant at the two673 sided $90 \%$ level according to a Student's T test.

674

675

676 
(a) EOF\#1 of onset date (var. expl. $=8.7 \%$ )

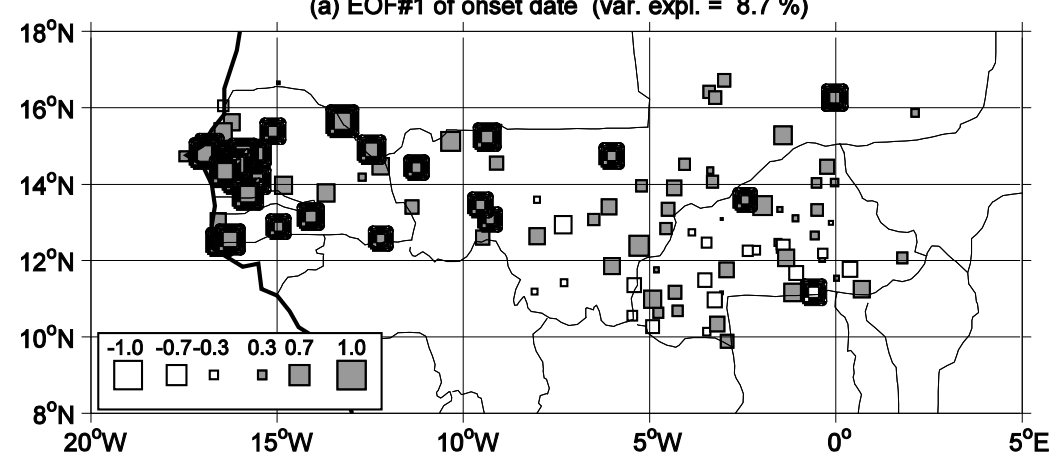

(b) EOF\#1 of seasonal amount (var. expl. = $38.1 \%$ )
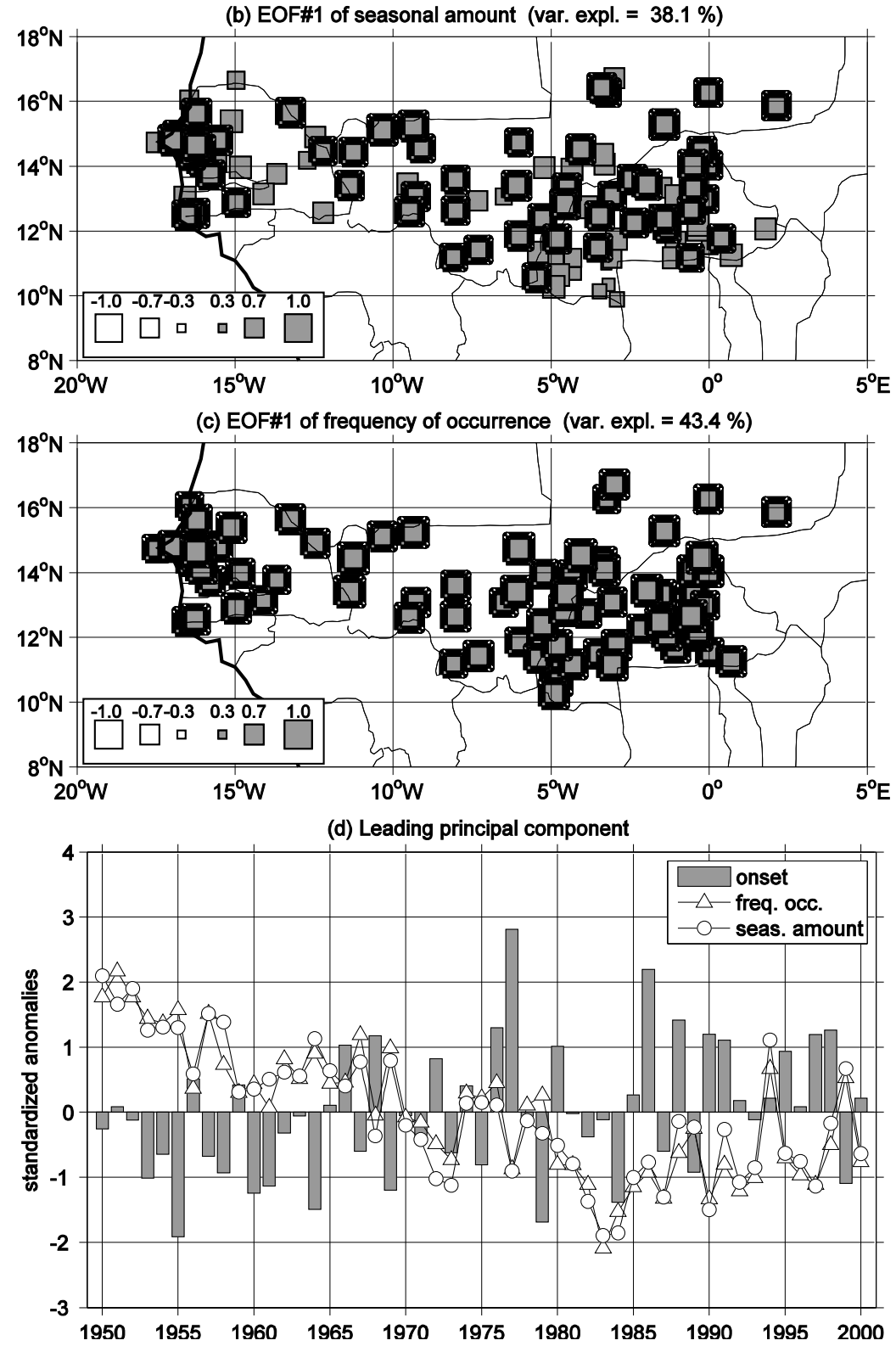

678Figure 5. (a) Leading unrotated empirical orthogonal function (EOF) modes of the local-scale 679 onset date, expressed as loadings, i.e. Pearson correlation between the corresponding Principal 680Component (PC) and the raw data. (b) Leading unrotated EOF of seasonal amount of rainfall. 681(c) Leading unrotated EOF of frequency of occurrence of rainfall $>1 \mathrm{~mm}$. (d) Leading principal 682component timeseries of onset date (bars), seasonal amount (circle) and frequency of 
683occurrence of rainfall (upper triangle). Bold squares displaying correlations statistically 684significant at the two-sided 95\% confidence level according to Bravais-Pearson test.

685

686

687

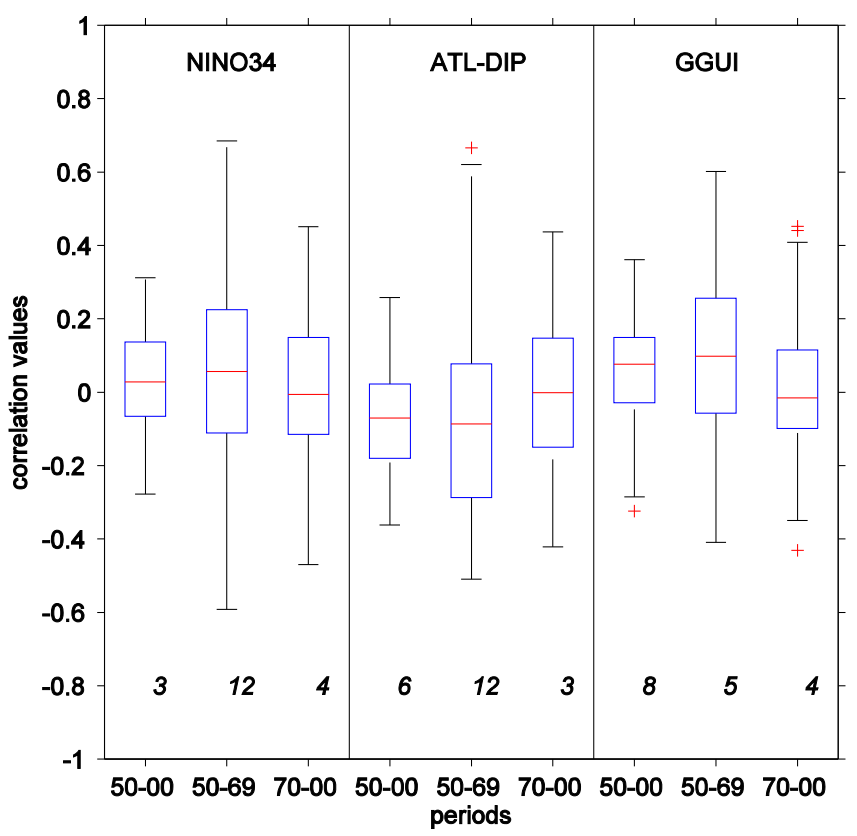

688

689Figure 6 : Boxplot of correlation coefficients between local-scale onset date and NINO3.4, 690Tropical Atlantic dipole and Guinea gulf SST index for periods 1950-2000, 1950-1969 and 6911970-2000. Boxes are bounded by the first quartite, and thirct quartite of the distribution and the 692imternal horizontal line is the median. Whiskers extend from the box out to the most extreme 693 tata value within 1.5 by the interquartile range. The boxes have lines at the lower quartile, 694median, and upper quartile values. The whiskers are lines extending from each end of the boxes 695to show the extent of the range of the data. Fhe outtiers are displayed by a cross. Outliers, 696displayed by a cross, are data with values beyond the ends of the whiskers. Italic values indicate 697the number of local-scale correlations significant at two-sided 95\% confidence level according 698to a random phase test (Janicot et al., 1996).

699

700 